\title{
A rare case of vaginal sarcoma in pregnancy
}

\section{Avinashi Kujur, Archana Roy*, Suma Velgin Ekka, Divya Gupta}

\section{Department of Obstetrics and Gynecology, Pandit Jawaharlal Nehru Memorial Medical College and DRBRAM} Hospital Raipur, Chhattisgarh, India

Received: 29 June 2020

Accepted: 01 August 2020

\section{*Correspondence:}

Dr. Archana Roy,

E-mail: archanaroy756@gmail.com

Copyright: (c) the author(s), publisher and licensee Medip Academy. This is an open-access article distributed under the terms of the Creative Commons Attribution Non-Commercial License, which permits unrestricted non-commercial use, distribution, and reproduction in any medium, provided the original work is properly cited.

\begin{abstract}
Vaginal Sarcoma is an extremely rare tumour in pregnancy. Authors are presenting a case report of a pregnant woman who presented with vaginal mass and urinary retention at 32 weeks of gestational age. USG confirmed a live baby with possibility of cervical fibroid. Before further investigations for diagnosis of the mass her emergency LSCS has to be done. Histopathology and immunohistochemistry then confirmed sarcoma.
\end{abstract}

Keywords: Pregnant woman, Vaginal sarcoma, Pregnancy

\section{INTRODUCTION}

Vaginal carcinoma is an exceedingly rare diagnosis constituting $2-3 \%$ of malignant neoplasms in female genital tract. ${ }^{1}$ Among variety of histological types, vaginal sarcomas represent only a fraction $(3.1 \%) .^{2}$ The aetiology is currently unknown and unrelated to pregnancy. For general population, the tumour runs a subclinical course and is diagnosed only 'by chance'. DES exposure, HPV infection, familial history, cervical cancer may be the cause in some women, still influence of pregnancy on initiation, promotion and development of sarcomas is unclear. ${ }^{3}$ Adding to this plethora, are the aggressiveness and poor 5-year survival rate of the tumour. ${ }^{4}$ Mortality rates are high depending on the stage of disease at the time of diagnosis. ${ }^{4}$ Management involves multidisciplinary approach considering maternal welfare as well as foetal life. ${ }^{4}$ Unfortunately, not much literature is available, hence authors tried to present this case report to further help in understanding course of this tumour in pregnancy.

\section{CASE REPORT}

A 20-year-old primigravida patient with 8 months of amenorrhea (31 week +4 day) developed lower abdominal pain and urinary retention for 1 month. She was catheterized at a peripheral center and was referred to our tertiary facility. Her vitals were stable and baseline antenatal investigations were within normal limits. She was given intravenous antibiotics, tocolytics, steroid coverage and magnesium sulphate for neuroprotection of fetus.

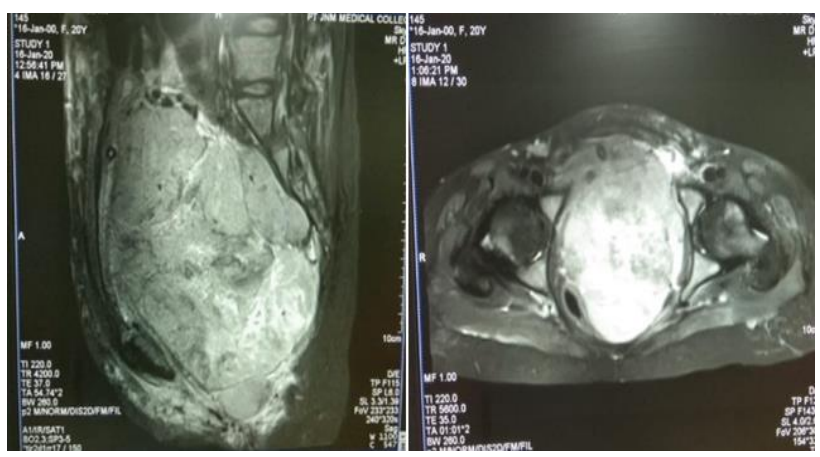

Figure 1: MRI of the mass in abdominopelvic cavity.

She denied any significant medical or family history.

On per speculum examination under anesthesia, a mass of around $10 \times 10 \mathrm{~cm}$ on lower third of left lateral vaginal 
wall extending posteriorly was seen. Mass was occupying whole of vagina. Pus discharge was present.

On per vaginal examination same firm, tender mass with regular margins was felt, however the origin couldn't be traced.

\section{USG pelvis findings}

USG pelvis findings demonstrated a large fairly defined lesion with multiple internal hypoechoic areas of size $14 \times 13 \times 11 \mathrm{cc}$ noted in pelvic region arising from cervix extending up to vagina showing peripheral vascularity suggestive of cervical fibroid with mild hematometra.

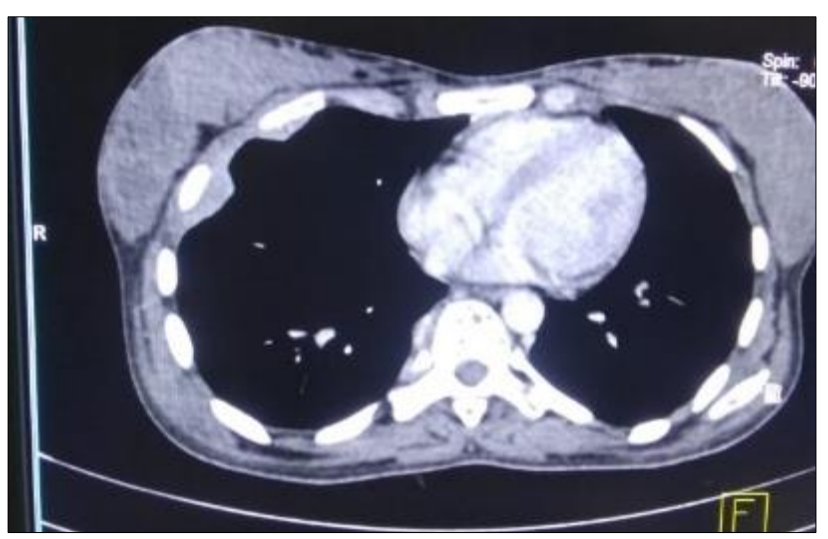

Figure 2: CT scan of chest pleural and lung metastasis.

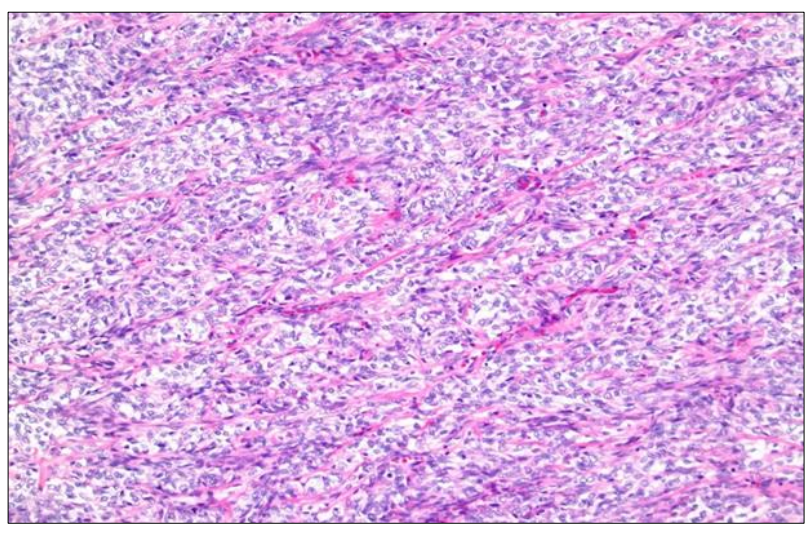

Figure 3: Histopathology of pleomorphic cells, hyperchromatic nuclei and prominent nucleoli.

Her MRI pelvis was planned but before it can be done at 32 weeks of GA (gestational age), she started leaking of amniotic fluid and went into preterm labor for which emergency LSCS was done. One-unit RCC was transfused intraoperatively as she was anemic preoperatively.

\section{Intra operative findings}

Intraoperatively, there was no visible mass from cervix. However, on palpation there was diffuse mass arising in pouch of Douglas extending into left pelvic wall, lower margins couldn't be reached, ovaries and fallopian tubes were normal. She delivered a viable male baby of $1.3 \mathrm{~kg}$ with APGAR 5 and 8. Due to low birth weight and prematurity baby was shifted to NICU and was discharged after 20 days.

\section{MRI findings}

In the post op period, her MRI abdomen was done. It showed a hyperintense soft tissue mass measuring $12.3 \times 11 \times 15.7 \mathrm{cc}$ in abdominopelvic cavity. The mass seems not to infiltrate parametrium and other pelvic structures suggesting a large leiomyoma with multifocal degeneration and areas of suspicious characteristics of malignant transformation. Multiple enlarged lymph nodes in bilateral inguinal and left internal iliac region. Metastasis noted in bone marrow of pelvis and bilateral femur. Her CT chest reported lung, pleural and bony metastasis.

\section{Pathological findings}

USG guided biopsy sample was taken and sent for HPR (histopathology report). Histopathology confirmed sarcoma with clear cell morphology. It showed sheets and clusters of malignant cells with clear cytoplasm and hyperchromatic nuclei separated by delicate fibrous septa. Patient was planned for immunohistochemistry and chemotherapy but before her chemotherapy could be started, she went into cardiac arrest and sadly died.

\section{DISCUSSION}

Not much is known of vaginal sarcomas. DES exposure, HPV infection, vaginal adenosis, cervical cancer, smoking, alcohol, HIV, vaginal irritation is among the certain risk factors but in many women, it developed without any of these. ${ }^{3}$ As in this case there appears to be no apparent risk factor. Pregnancy induces many hormonal, molecular, cellular and anatomic transformations in genital tract. Overlapping of these changes with cancerous changes makes diagnosis challenging. Bell et al reported the Stanford Criteria for histological diagnosis of malignant smooth muscle tumors which includes presence of at least two features among diffuse to severe atypia, a mitotic count of at least 10 mitotic figures/10 high power fields and tumor necrosis. ${ }^{5}$ This criterion differentiates benign from malignant smooth muscle tumors. In the current case, expert pathologist confirms sarcoma by the same.

In a 20-year descriptive cohort study on management and outcome in women diagnosed with cancer during pregnancy by Jorine de Haan et al, $88 \%$ of women had livebirth, $48 \%$ of which had preterm deliveries. ${ }^{6}$ They recorded more NICU admissions in women with gastrointestinal tumors (OR 7.13,95\% CI 2.86-17.7) than any abdominal or cervical carcinomas (OR $0.30,95 \%$ CI $0.17-0.55)$. Similarly, in a literature review performed by 
Matsuo et al from 1955-2007 which includes 40 cases of genital sarcoma. ${ }^{7} 37.5 \%$ were uterine sarcomas whereas $12.5 \%$ were of vaginal sarcoma. Based on this review, there are two peaks of onset of symptoms, first trimester $(27.5 \%)$ and third trimester (50\%). Most common presenting symptom was mass $(42.5 \%)$ followed by abdominal pain $(30 \%)$ and vaginal bleeding $(22.5 \%)$. $22.5 \%$ cases were found fortuitously. $82.5 \%$ of women had livebirth with mean birthweight of $2.8 \pm 0.79 \mathrm{~kg}$. Commonest maternal complication was preterm labor. 2 , 3 and 5-year cumulative survival rates were $60 \%, 38 \%$, and $17 \%$, respectively. In this case also, the woman had a preterm baby of $1.3 \mathrm{~kg}$ by LSCS with admission in nursery. Prematurity is at the root for many neonatal and childhood complications. According to WHO report 2018, preterm birth complications are the leading cause of death in under 5 age group. Keeping this in view prevention of iatrogenic prematurity in babies of cancer patients should be top priority. According to American cancer society 5-year survival rate of vaginal carcinoma with spread to distant body parts is only $19 \%$ as in this case. $^{4}$

\section{CONCLUSION}

Primary vaginal sarcoma is a rare gynecological tumor during pregnancy. Information on behaviour of this tumor in pregnancy is available only through few case reports. Hence vaginal carcinomas should be a differential diagnosis for an obstetrician in women presenting with pelvic mass. As sarcoma runs a fast course hence timely detection by biopsy and immunohistochemistry is paramount. Treatment options seems to be less in a pregnant woman. Involvement of obstetricians, gynecological oncologists and paediatricians may help in prompt management and better outcome of both the lives.

\section{ACKNOWLEDGMENTS}

Authors would like to thank husband of the woman who gave consent to publish the case report for the betterment of other patients.
Funding: No funding sources

Conflict of interest: None declared

Ethical approval: Not required

\section{REFERENCES}

1. Berek JS, Berek DL. Berek an Novak's Gynecology. South Asian Edition. 2019;16:1066.

2. Berek JS, Hacker N. Gynecologic oncology, Lippincott Williams and Wilkins, Philadelphia, Pa, USA, $5^{\text {th }}$ edition; 2010.

3. Vaginal cancer risk factors and prevention. Am Cancer Society. 2020. Available at: https://www.cancer.org/cancer/vaginalcancer/causes-risks-prevention.html. Accessed on $11^{\text {th }}$ May 2020.

4. American Cancer Society's (ACS) publication, Cancer Facts and Figures, 2017. Available at: https://www.cancer.org/content/dam/cancerorg/research/cancer-facts-and-statistics/annualcancer-facts-and-figures/2017/cancer-facts-andfigures-2017.pdf. Accessed on $11^{\text {th }}$ May 2020.

5. Bell SW, Kempson RL, Hendrickson MR. Problematic uterine smooth muscle neoplasms. A clinicopathologic study of 213 cases. Am J Surg Pathol. 1994;18(6):535-58.

6. de Haan J, Verheecke M, Calsteren KV, Calster BV, Shmakov RG, Gziri MM, et al. Oncological management and obstetric and neonatal outcomes for women diagnosed with cancer during pregnancy: a 20-year international cohort study of 1170 patients. Lancet Oncol. 2018;19(3):337-46.

7. Matsuo K, Eno ML, Im DD, Rosenshein NB. Pregnancy and genital sarcomas: a systematic review. Am J Perinatol. 2009;26(7):507-18.

Cite this article as: Kujur A, Roy A, Ekka SV, Gupta D. A rare case of vaginal sarcoma in pregnancy. Int J Reprod Contracept Obstet Gynecol 2020;9:3906-8. 